7. Duxbury F. Recognising domestic violence in clinical practice using the diagnoses of posttraumatic stress disorder, depression and low self-esteem. Br J Gen Pract 2006; 56(525): 294-300.

DOI: 10.3399/bjgp11X588385

\section{Pulse oximetry in primary care}

Plüddeman et al' write about the use of pulse oximetry. This seems to be one of the new trio of diseases - the other two being D-dimers for blood clots, and troponin for the detection of myocardial damage.

All three tests need to be used appropriately in their clinical situation. It seems from observation that the $\mathrm{SpO}_{2}$ can vary significantly over a fairly short period of time, and with an error of $2 \%$ this can make a big difference to the reliability of the reading. This becomes especially true of those with chronic obstructive pulmonary disease - when their normal saturations can be really quite low.

All three tests need to be used appropriately and co-related to the clinical picture. It is very tempting to use anything numerical as having greater power than softer signs of speech, use of accessory muscles, and primarily, clinical history. III advised use of these tests will inevitably lead to increasing hospital admission, maybe particularly in the out-of-hours care of patients.

In assessing a patient, there are often pivotal cues, symptoms, or signs that open up the diagnosis. I think we all develop a primacy of signs, those bits of information that we rely more heavily on in making clinical decisions. We can allow something with a number attached, especially with a guideline behind it, to become the primary sign. However, I believe good general practice involves weighing up history, examination, and other data. If our action is determined by one or two bits of information I think we will lose our touch as generalists.

Pulse oximeters are useful tools as part of our armamentarium. But if doctors continue to become more risk averse, and rely on gadgets rather than the whole clinical picture, iatrogenic disease will continue to increase.

Chris Gunstone,

36, Holly Street, Burton upon Trent, Staffs, DE15 9ET. E-mail: chris.gunstonelanhs.net

\section{REFERENCE}

1. Plüddemann A, Thompson M, Heneghan C, Price C. Pulse oximetry in primary care. Br J Gen Pract 2011; 61(586): 358-359.

DOI: 10.3399/bjgp11X588394

\section{Tips for GP trainees working in general surgery}

We welcome the recent very helpful article from Smith et al' which has broad relevance to all those who are not career surgeons when they embark on their surgical attachments. This article sensibly recognises there is often more than one way to investigate and, for instance when considering renal colic, offers wise advice that will limit unnecessary exposure to radiation.

We cannot, however, agree with the advice, 'If unsure whether an erect chest $X$ ray and abdominal $X$-ray is warranted, get one anyway.' Exposure to potentially unnecessary radiation should not be ignored and an abdominal $X$-ray in the context of abdominal pain is one of the most overused plain films, ${ }^{2}$ with each abdominal $X$-ray being equivalent to approximately 35 chest $\mathrm{X}$-rays. ${ }^{3}$

Selection of the most appropriate imaging is often difficult, and guidance, such as Making the Best use of Clinical Radiology Services ${ }^{4}$ produced by the Royal
College of Radiologists, can be extremely useful in this setting. This document is available online throughout the NHS, is evidence based, and provides guidance both as to which investigations may be helpful in each clinical context, and provides a reference if you are asked to justify why you did not feel a particular investigation was appropriate. Radiologists are also generally very happy to offer advice on what is appropriate and may be a useful port of call if you find yourself being asked to request investigations routinely that do not clearly conform to such guidelines.

We suggest adding a point zero: always think for yourself. Seek advice when you need it, but be prepared to justify your own actions.

\section{JA Allred}

Foundation Year 1 Doctor (Radiology), Radiology Department, Royal Cornwall Hospital, Truro TR1 3LJ.

Email: james.allredarcht.cornwall.nhs.uk

RD Proctor,

Consultant Radiologist, Radiology

Department, Royal Cornwall Hospital, Truro TR1 3LJ.

\section{REFERENCES}

1. Smith L, Cruikshank R, Burkes M. Tips for GP trainees working in general surgery. $\mathrm{Br} J \mathrm{Gen}$ Pract 2011; 61(587): 418-419.

2. Singh RK, McCoubrie P, Burney K, Miles JA. Teaching medical students about radiation protection - what do they need to know? Clin Radiol 2008; 63(12): 1344-1349

3. Davies HE, Wathen CG, Gleeson FV. The risks of radiation exposure related to diagnostic imaging and how to minimise them. BMJ 2011; 342: 589-593.

4. The Royal College of Radiologists. Making the best use of clinical radiology services: referral guidelines. London: The Royal College of Radiologists, 2007.

http://www.rcr.ac.uk/content.aspx?PagelD=995 laccessed 18 July 2011).

DOI: 10.3399/bjgp11X588402 